\title{
Ultra High-Frequency Electric Installation with a Hybrid-Type Working Chamber
}

\author{
Midhat Tuhvatullin ${ }^{1 *}$, Yuri Arkhangelsky², Rustam Aipov², Eduard Khasanov ${ }^{3}$ \\ ${ }^{1}$ Department of Power Supply and Automation of Technological Processes, Federal State Budgetary Educational Establishment \\ of Higher Education "Bashkir State Agrarian University", 50-letia Octyabrya str., 34, Ufa 450001, Russian Federation \\ 2 Department of Electric Machines and Equipment Department, Federal State Budgetary Educational Establishment of Higher \\ Education "Bashkir State Agrarian University", 50-letia Octyabrya str., 34, Ufa 450001, Russian Federation \\ ${ }^{3}$ Department of Agricultural and Technological Machines, Federal State Budgetary Educational Establishment of Higher \\ Education "Bashkir State Agrarian University", 50-letia Octyabrya str., 34, Ufa 450001, Russian Federation
}

Corresponding Author Email: mituhvatullin@ rambler.ru

https://doi.org/10.18280/mmep.080613

Received: 26 May 2021

Accepted: 15 September 2021

\section{Keywords:}

electric installation, hybrid-type working chamber, non-thermal and thermal UHF modification, UHF electromagnetic field

\begin{abstract}
Ultra-high frequency (UHF) electric installations, using the energy of UHF electromagnetic oscillations, can perform thermal UHF modification of dielectric materials and products. As a result, its properties and parameters change in an object processed in a UHF electromagnetic field faster and more uniformly than when the heat is transferred to a heated dielectric by thermal conductivity, convection, thermal radiation. The exact change in the properties and parameters of polymers of living and inanimate nature, uniform in volume and significantly in a shorter time spent in a UHF electromagnetic field, can be obtained in UHF electrical installations, and practically without heating the object as a result of the so-called non-thermal UHF modification. The paper proposes the design and design of a UHF electric installation with a hybridtype working chamber. Such a working chamber makes it possible to simultaneously carry out non-thermal UHF modification of a polymer and thermal UHF modification of a dielectric in one installation. A UHF electric installation with a hybrid-type working chamber is cheaper. It takes up less space than two separate installations producing the same products with the same productivity.
\end{abstract}

\section{INTRODUCTION}

Heat treatment of dielectric media, materials, and products is a technological process widely demanded in various industries, agriculture, medicine, and everyday life. Traditionally, heat from the heater to the surface of the heated object is supplied by thermal conductivity, convection, thermal radiation, but the dielectric is a heat insulator, its thermal conductivity coefficient is small, and the heating of the entire volume of the heated dielectric is slow. The volume of the material is heated unevenly [1].

Heating of the dielectric due to the energy of UHF electromagnetic oscillations in the electromagnetic field occurs much faster and more uniformly since the propagation of an electromagnetic wave in the processed dielectric occurs at a tremendous speed, and heat release occurs in each elementary volume of the processed object $[2,3]$.

Scientists, such as Arkhangelsky et al. [4], Dobrodum and Arkhangelsk [5], Karampatea and Siakavara [6], Monton et al. [7] are researching scientific foundations for the design and development of structures for UHF electrical installations and their elements. Nirmaan et al. [8], Szałatkiewicz et al. [9], Xu et al. [10] do the research and development of technological processes of UHF heat treatment of food products. The UHF effect on biopolymers was studied in Dobrodum and Arkhangelsk [11], Li et al. [12]. These studies are of great scientific importance and occupy a worthy place in the development of UHF electrothermy.
In recent years, systematic work has been carried out on UHF energy in agriculture. The research by Khasanov [13], Sivyakov and Grigoryan [14], Stepanenko and Kazhevnikov [15], Weng et al. [16], is underway in the field of non-thermal UHF modifications. Zlobina [17], mathematical modelling of UHF heat treatment Trigorly et al. [18], Tukhvatullin et al. [19], Zakharov et al. [20].

In this paper, we propose a UHF electric installation with a hybrid-type working chamber, which simultaneously implements a non-thermal UHF modification of a polymer and a thermal UHF modification of a dielectric. We also consider the design issues of such an installation.

The following scientists in our country are engaged in research on UHF action on polymers: Arkhangelsky et al. [4], Dobrodum and Arkhangelsk [11], Zlobina [17], and abroad: Chen et al. [21], Feng et al. [22], Ghasri et al. [23], Hong and Kim [24], Hu et al. [25], Jia et al. [26], Liu et al. [27], Zhan et al. [28], Zhang et al. [29], Bulat, M.P. et al. [30], Bulat, P.V. et al. [31].

A UHF electrical installation implements a non-thermal UHF modification of a polymer or a thermal UHF modification of a dielectric.

In this paper, we propose a UHF electric installation with a hybrid-type working chamber, which simultaneously implements a non-thermal UHF modification of a polymer and a thermal UHF modification of a dielectric. We also consider the design issues of such an installation.

Research Purpose: development of a UHF electric 
installation with a hybrid-type working chamber.

\section{Research Objectives:}

- To develop the layout of the UHF electric installation from the working chamber of the hybrid type.

- To consider the design issues of UHF electrical installations with hybrid working chambers.

\section{METHODS}

The synthesis of working chambers and mathematical modelling of thermal UHF modification technological processes is carried out based on an agreed boundary value problem of electrodynamics and heat and mass transfer.

The synthesis of working chambers of non-thermal UHF modification is carried out based on solving the Maxwell equation.

Electrical circuits ' theory is used in the synthesis of working chambers with a layered filling of the working chamber with dielectrics.

When choosing options for the layout of a UHF electrical installation from a working chamber of a hybrid type, technical and economic calculations are used.

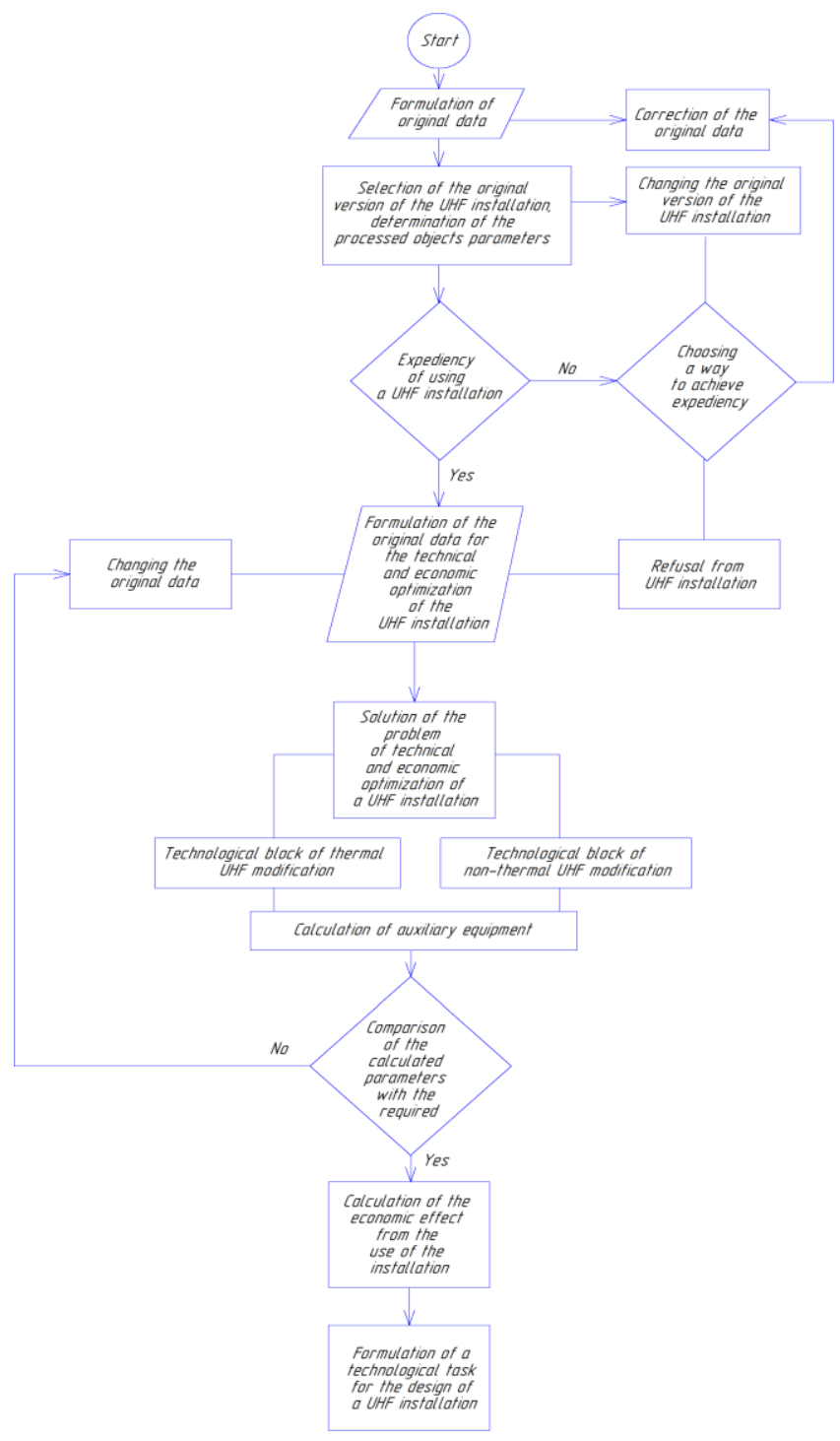

Figure 1. Block diagram of the design algorithm for a UHF electrical installation with a hybrid-type working chamber
Figure 1 shows a block diagram of the design algorithm for a UHF electrical installation with a hybrid-type working chamber.

When formulating the initial design data for a UHF electrical installation with a hybrid-type working chamber, a decision is made to start designing to obtain a commercial product that has undergone non-thermal and thermal UHF modification. When deciding on the amount of work to be done, one should judge by marketing research results on the product market.

When choosing the initial version of a UHF electrical technological installation with a hybrid-type working chamber, the simplest version of the installation layout should be chosen. At this stage, one has to solve collecting and determining the modified vows' parameters. It is a challenging and critical design stage. The use of approximate values at the stages of the synthesis of working chambers, mathematical modelling of the technological process, for example, parameters such as the relative permittivity $\varepsilon$ and dielectric loss tangent $\operatorname{tg} \delta$ of the processed objects, thermos-physical parameters can lead to unacceptable errors in calculating the geometry of the working chambers and their modes of operation.

Strictly speaking, determining these parameters is the task of materials science, but the design-oriented installation carries out their measurement for specific polymers and dielectrics.

It should be noted that the parameters of the non-thermal UHF modification of polymers have been studied less than the parameters of objects subject to thermal UHF modification. Therefore, when designing a UHF electrical installation with a hybrid-type working chamber, special care should be taken when calculating the working chamber of a non-thermal UHF modification of a polymer. First of all, you need to know the values of optimal tensions $E_{o p t}$, frequency $f_{\text {opt }}$ and non-thermal modification time $\tau_{\text {opt }}$

The practicality of building the planned UHF electrical installation with a hybrid-type working chamber is being clarified at the next design stage. The comparative economic effect is calculated.

$$
\Delta E_{\sum}=\Delta E_{\sum^{h}}-\Delta E_{\sum^{n}}-\Delta E_{\sum^{t h}}
$$

where, $\Delta E_{\sum h}-$ is the net profit of a UHF electrical installation with a hybrid-type working chamber on an interval of 1 year;

$\Delta E_{\sum n}-$ is the net profit of a UHF electric installation of a non-thermal UHF modification of a polymer on an interval of 1 year;

$\Delta E_{\sum t h}-$ is the net profit of a UHF electric installation of a thermal UHF dielectric modification interval of 1 year.

The productivity of the working chamber of a hybrid type for both processed objects must, of course, be equal to the productivity of separate installations of non-thermal UHF and thermal UHF modifications of the same processing objects.

Suppose $\Delta E_{\Sigma}>0$ the design and use of a UHF electrical technological installation with a hybrid-type working chamber are advisable $\Delta E_{\Sigma}<0$. Then a method should be chosen to achieve the feasibility of using an installation with a hybridtype working chamber. It can be an adjustment to the original design data or a change to the original installation.

In the case of technical and economic optimization of a UHF electrical technological installation with a hybrid-type working chamber, the net profit (economic efficiency) formula should be used as an objective function: 


$$
E_{\sum}=E_{\sum C O N S T}-E_{\sum V A R}
$$

where,

$E_{\Sigma C O N S T}-$ is the constant part of $E_{\Sigma}$;

$E_{\sum V A R}$ is the variable part.

The finding is then reduced to finding the conditions under which $E_{\text {¿VAR.MIN }}$ is achieved so that the structure and parameters of the designed installation, which has the maximum economic efficiency, are determined.

So the technical and economic optimization of a UHF electric installation with a hybrid-type working chamber is reduced to solving the system of equations

$$
\left\{\begin{array}{l}
\frac{\partial E_{\sum V A R}}{\partial x_{1}}=0 \\
\frac{\partial E_{\sum_{V A R}}}{\partial x_{2}}=0 \\
\cdots \\
\frac{\partial E_{\sum_{V A R}}}{\partial x_{n}}=0,
\end{array}\right.
$$

where, $x_{1}, x_{2}, \ldots x_{n}-$ are the independent parameters, on which $E_{\sum V A R}$ depends, that is, the global minimum of the dependence is determined.

$$
E_{\sum V A R}=E_{\sum V A R}\left(x_{1}, x_{2}, \ldots x_{n}\right)
$$

In addition to independent parameters, $E_{\sum V A R}$ it also depends on the standard parameters. The standard parameters do not vary during the calculation $E_{\sum V A R . M I N}$ they remain specified. Dependent parameters in calculations should be determined through independent parameters.

Independent parameters are usually the number of UHF generators $M$ in one installation, UHF power $P$ and frequency $f$ (wavelength $\lambda$ ) of the UHF generator. If $M$ and $P$ are explicitly included in the $E_{\sum V A R}$ expression, then $f$ is not. As a first approximation, we can assume that:

$$
V=\lambda^{3} ; S=(3 \ldots 6) \lambda^{2}
$$

where, $V$ and $S$ are the volume and surface area of the heated dielectric;

$\lambda$ is the generator wavelength.

Such dependent parameters present a big problem as the prices of installation elements. Analytical dependences of these parameters on other parameters, strictly speaking, are impossible, but it is possible to represent these prices depending on the UHF power $P$.

$$
C=a P^{2}+b P+c
$$

where, $a, b, c$ are invariables.

This optimization method applies to the working chambers of the thermal UHF modification and the non-thermal UHF modification's working chambers if this modification can be applied at any value $E$.

Suppose the non-thermal UHF modification is performed only at a given value $E$ in the working chamber of the non- thermal UHF modification. In that case, the power of the UHF electric installation with a hybrid-type chamber is selected, taking into account the section of the waveguide, the working chamber of the non-thermal UHF modification is such that in this waveguide $E=E_{\text {opt }}$. The frequency $f$ of the UHF energy source is selected from those approved for use in UHF electrical technology, in which the effect of non-thermal UHF modification occurs.

The length of the homogeneous waveguide of the working chamber of the non-thermal UHF modification is chosen such that the intensity at its input was $E_{o p t}+\Delta E_{\text {opt }}$ - output $E_{o p t}-\Delta E_{o p t}$ (Figures 2 and 3), that is,

$$
l=\frac{1}{2 \alpha} \ln \frac{E_{o p t}+\Delta E_{o p t}}{E_{o p t}-\Delta E_{o p t}}
$$

where, $\alpha$ is the attenuation coefficient in the waveguide partially filled with the processed polymer;

$\Delta E_{\text {opt }}$ is the permissible deviation of the tension $E$ from the optimal value in the non-thermal $\Delta E_{\text {opt }}$ UHF modification.

In the thermal UHF modification's technological block, a standing wave chamber is not used as a working chamber. The input and output locks of this working chamber's cavity resonator reduce its Q-factor, which makes it energetically ineffective.

The synthesis of the working chambers of this technological unit based on chambers with travelling water and ray-type chambers is carried out by solving the coordinated boundaryvalue problem of electrodynamics and heat and mass transfer $[4,19]$.

$$
\begin{gathered}
\operatorname{rot} H=G+\frac{\partial D}{\partial t} ; \operatorname{rot} E=-\frac{\partial B}{\partial t} ; \begin{array}{c}
\operatorname{div} B=0 \\
\operatorname{div} D=0
\end{array} \\
\frac{\partial \theta}{\partial t}+\nu \nabla \theta=k_{11} \nabla^{2} \theta+k_{12} \nabla^{2} U+k_{13} \nabla^{2} p+\frac{P_{S P}}{c_{\partial} \rho_{\partial}} \\
\frac{\partial U}{\partial t}+v \nabla U=k_{21} \nabla^{2} \theta+k_{22} \nabla^{2} U+k_{23} \nabla^{2} p ; \\
\frac{\partial p}{\partial t}+v \nabla p=k_{31} \nabla^{2} \theta+k_{32} \nabla^{2} U+k_{33} \nabla^{2} p
\end{gathered}
$$

where,

$H, E$ are the strengths of the magnetic and electric field of the electromagnetic wave;

$G$ is the conduction current density (when heating the dielectric);

$B, D$ are the magnetic and electric induction of the electromagnetic field;

$$
\theta=T-T_{0}
$$

$T, T_{0}$ are the current and initial temperatures of the processed object;

$U$ is the specific moisture content of the processed object;

$p$ is the pressure of water vapour in the processed object;

$v$ is the speed of transportation of the processed object in the working chamber;

$k_{11}, k_{12}, k_{33}$-are heat and mass transfer coefficients;

$P_{S P}$ is the specific power absorbed by the processed object;

$c_{\partial}, \rho_{\partial}$ are the specific heat and density of the processed object. 


\section{STUDY RESULTS}

Experimental studies of non-thermal UHF modification of polysulfone films, polycaproamide filaments and epoxy compounds have shown that the properties and parameters of polymers change during a short time UHF electromagnetic field practically without heating. But at such an electromagnetic field, strength $E$ in the working chamber of a non-thermal UHF modification can be achieved when using a powerful UHF generator in a UHF electrical installation. And this UHF power, after the non-thermal UHF modification, remained practically unchanged. In the UHF, the electrical installation of the non-thermal UHF modification has to be dissipated in the flowing water flow of the ballast load connected to the waveguide of the working chamber of the non-thermal UHF modification. Such an installation has a very decent economic efficiency, but the efficiency is essentially zero.

But it is possible to determine the energy efficiency of a UHF electrical installation of a non-thermal UHF modification by connecting a non-ballast load to the output of its working chamber and the working chamber of a thermal UHF modification of another dielectric (Figure 2).

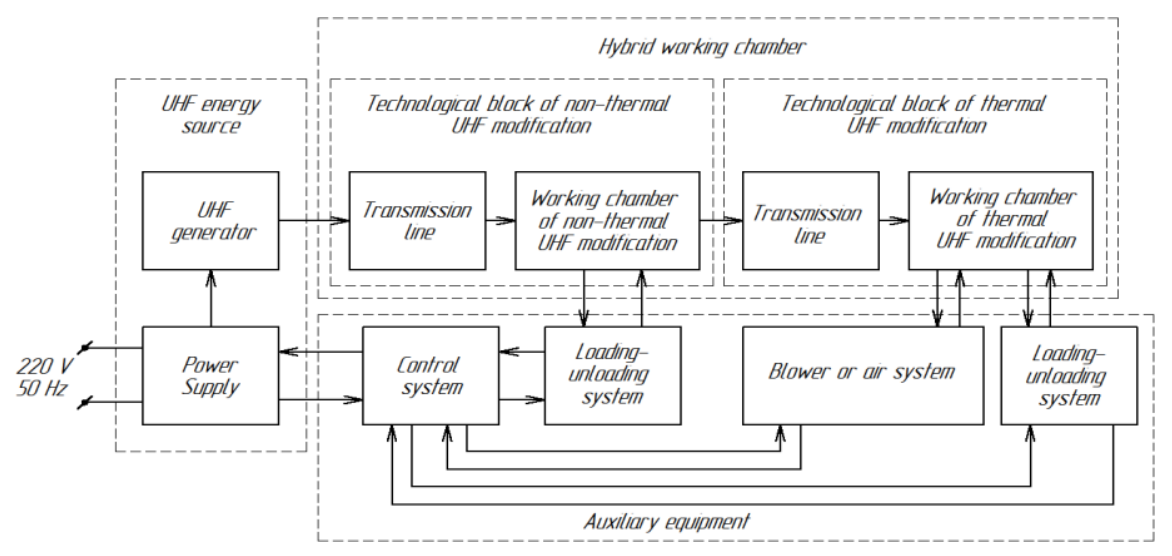

Figure 2. Block diagram of a UHF electrical installation with a hybrid-type working chamber

The working chamber of such an installation was called hybrid [11]. It simultaneously performs non-thermal UHF modification of the polymer and thermal UHF modification of the dielectric. A few works have been published on this topic; there is still no systematic consideration of UHF electrical installations with working chambers of a hybrid type [11,32].

The installation shown in Figure 2 produces two types of products; its economic efficiency is higher than that of a separate installation of non-thermal or thermal UHF modification. Its efficiency, that is, energy efficiency, is equal to the maximum achievable value.

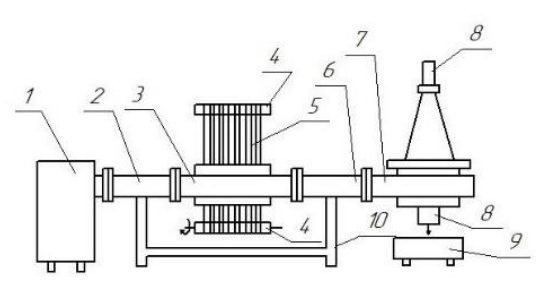

Figure 3. The layout of a UHF electric installation with a hybrid-type working chamber: 1 - UHF energy source; 2 transmission line (rectangular waveguide); 3 - working chamber of non-thermal UHF modification; 4 - a system for loading and unloading a working chamber of a non-thermal UHF modification; 5 - polymer filaments subjected to nonthermal UHF modification; 6 - transmission lines (rectangular waveguide); 7 - working chamber of thermal UHF modification; 8 - a system for loading and unloading the working chamber of the thermal UHF modification; 9 -

receiving hopper, which has passed the thermal UHF modification of the fluid flow; 10 - stand

A UHF electric installation with a hybrid-type working chamber, shown in Figure 3, modifies polycaproamide filaments, which increases the tensile strength of the filaments, and provides thermal UHF modification of liquids in the flow, which reduces its viscosity. The working chamber structure of a non-thermal and thermal UHF modification in a hybrid-type working chamber is explained in Figure 4. Figure 4a shows a cross-section of a working chamber of non-thermal UHF modification filaments. Figure $4 \mathrm{~b}$ shows a working chamber's cross-section with a travelling wave, partially filled with a heated dielectric, used as a working chamber of the thermal UHF modification.

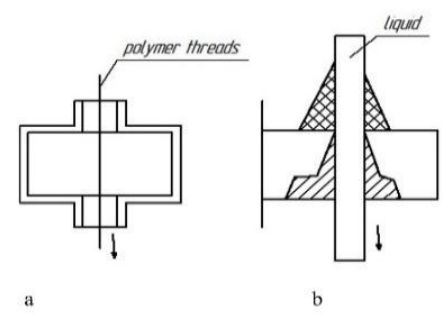

Figure 4. Cross-sections of the working chambers of technological units of a UHF electrical installation with a hybrid-type working chamber: a - rectangular waveguide with a layer of processed threads; $b$ - a camera with a travelling wave on an irregular circular waveguide partially filled with a processed object

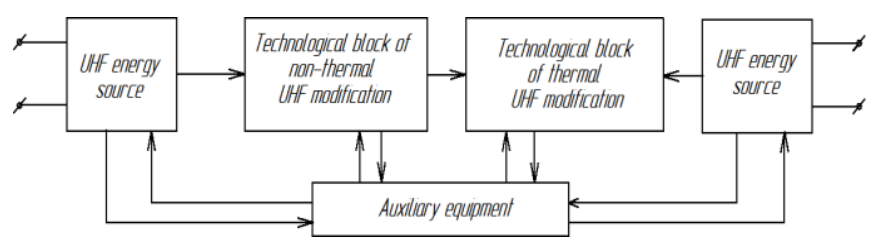

Figure 5. Block diagram of a UHF electrical installation with a hybrid-type working chamber 
The UHF power required to create an electromagnetic field of intensity $\mathrm{E}$ in the working chamber should be supplied to the working chamber's input of a non-thermal UHF modification from a UHF energy source which the nonthermal UHF modification of this polymer is most effective. Suppose, at the same time, insufficient UHF power for the heat treatment of the dielectric is supplied to the working chamber's input of the thermal UHF modification. In that case, additional UHF power should be supplied to this working chamber from another source of UHF energy (Figure 5).

An example of building such a working chamber is shown in Figure 6.

On the other hand, a UHF power is supplied to the input of the working chamber of the thermal UHF modification, which exceeds the power required for the thermal UHF modification of a given dielectric. Then the transmission line of the technological unit of the thermal UHF modification must divide the incoming UHF power so that this UHF power is spent on the thermal UHF modification, but in two working chambers (Figure 7).

A plant with such a structure can produce two or three types of products. Finally, suppose the UHF energy source generates UHF power that significantly exceeds that required for a nonthermal UHF modification of the polymer, then at the input of the technological unit of the non-thermal UHF modification the polymer. In that case, there must be a UHF power divider that supplies UHF power to the second technological unit of the non-thermal UHF modification of the same or another polymer. The further supply of UHF power must follow it to the second technological unit of thermal UHF modification of the same or another dielectric (Figure 8).

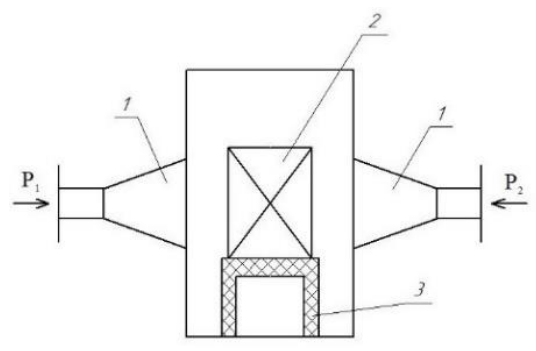

Figure 6. The layout of the beam-type chamber as a working chamber of the thermal UHF modification, powered by two

UHF energy sources: 1 - radiating horns; 2 - dielectric subject to thermal UHF modification; 3 - stand; $\mathrm{P}_{1}, \mathrm{P}_{2}$ - UHF power supplied to the working chamber from two sources of UHF energy

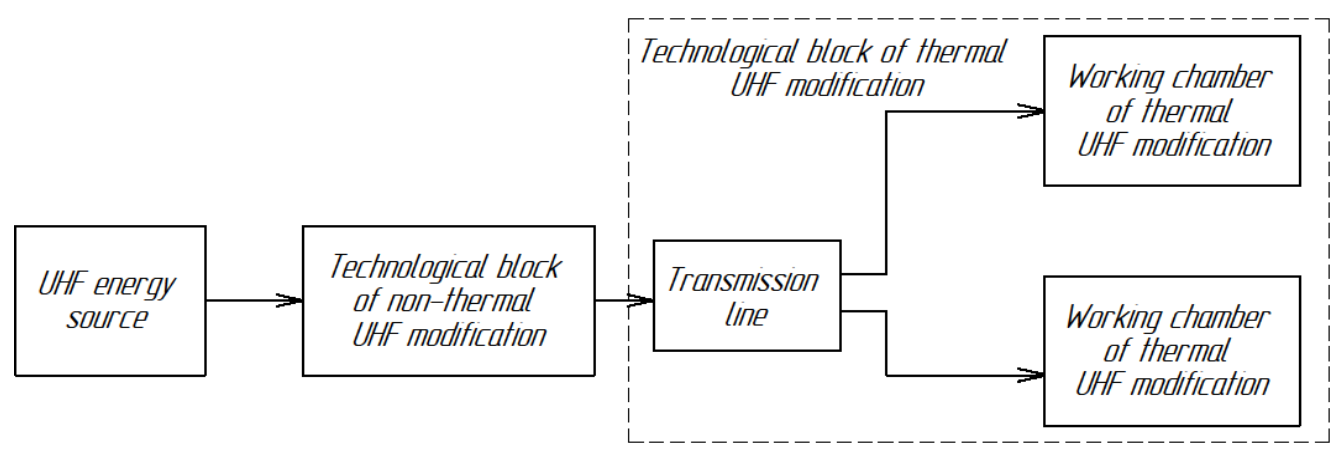

Figure 7. Block diagram of a UHF electrical installation with a hybrid-type working chamber (with two working chambers of a thermal UHF modification)

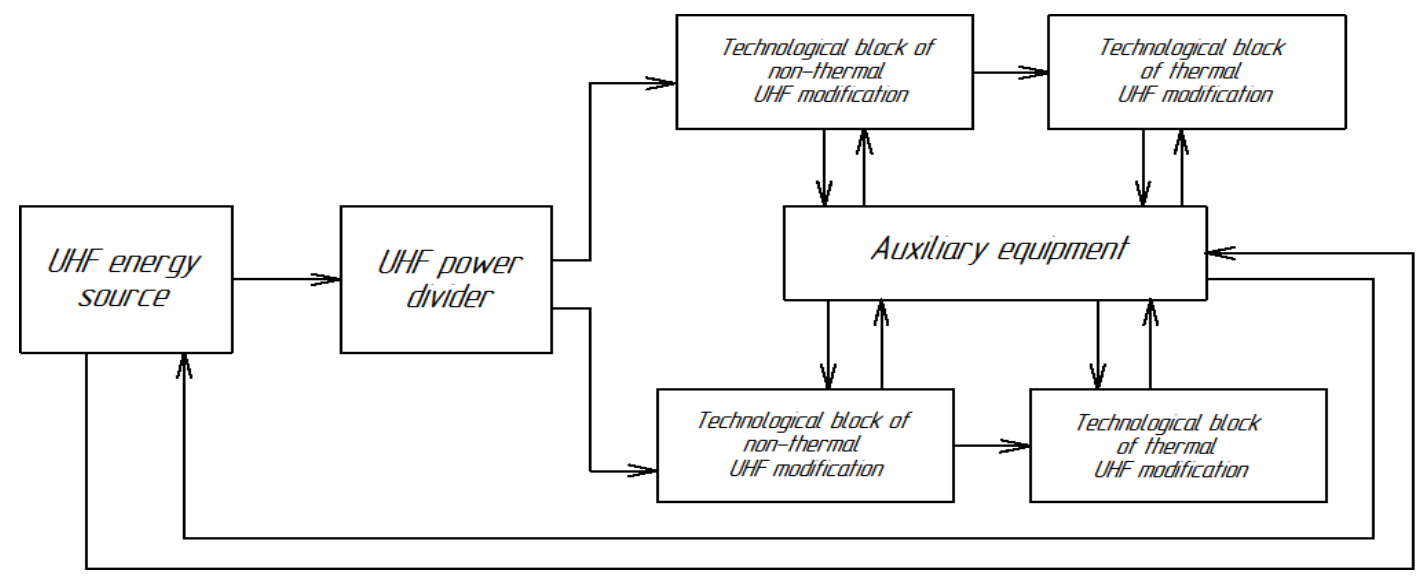

Figure 8. Block diagram of a UHF electrical installation with a hybrid-type working chamber with four technological blocks

In such UHF electrical installations, two, three or four different products can be processed simultaneously.

A non-thermal UHF modification lasts a few seconds. Therefore, the working chamber of a non-thermal UHF modification must operate in a systematic mode, and therefore a thermal UHF modification must be carried out in the same mode. The periodic mode of its operation will require switching off the UHF energy source when the polymer's nonthermal UHF modification is stopped. It will lead to the appearance of the initial and final rejects of the non-thermal UHF modification.

There may be a production need to coordinate the capacities of a UHF electrical installation with a hybrid-type working chamber for non-thermal and thermal UHF modifications. 
As for the mathematical modelling of the technological process of non-thermal UHF modification of polymers, we note that there is no generally accepted picture of the processes occurring in this case. This modification takes place in a few seconds with practically no heating, and therefore mathematical modelling of this process can be omitted.

Finally, the theory of electrical circuits should be used in the calculations of beam-type chambers and the heat treatment processes of layered dielectrics (Figure 9).

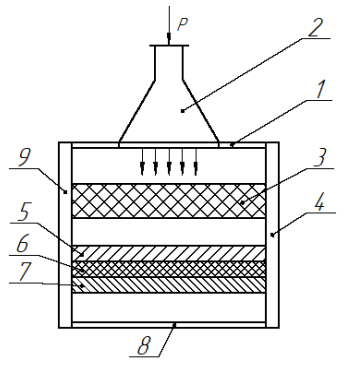

Figure 9. Beam-type chamber of thermal UHF dielectric modification: 1,8 - working chamber; 2 - horn radiator; 3 quarter-wave matching transformer; 4 - exit gateway; 5,6,7 processed layered dielectric; 9 - entrance gateway

Then, using the long line theory [4], you can calculate the input resistance of the air layer under layer 7 of the dielectric. This resistance will be the load resistance of the long line segment - dielectric layer 6 . In turn, the input resistance of layer 6 is the load resistance of the dielectric layer 5 . The use of a quarter-wave matching transformer 3 makes it possible to match the layered dielectric with the horn radiator 2 , that is, to obtain the maximum energy efficiency of the working chamber.

Auxiliary equipment of a UHF electrical installation with a hybrid-type working chamber is designed similarly for UHF electrical installations of non-thermal and thermal UHF modification.

If the comparison of the calculated parameters in the projected installation with the required modes diverges, the projected installation's initial data should be changed.

The design is completed by calculating the economic effect from using a UHF electrotechnological installation with a hybrid-type working chamber and preparing a technical assignment for the design of this installation.

\section{DISCUSSION}

In this paper, three types of UHF electrical technological installations are considered:

- a relatively new, gaining popularity type of installation that implements non-thermal UHF modification of polymer materials and products;

- a well-mastered type of installation with a proven design procedure that implements the thermal UHF modification of the dielectric;

- a new type of installation with a working chamber of a hybrid type simultaneously implements a non-thermal UHF modification of a polymer and a thermal UHF modification of a dielectric.

The information presented in this work on these UHF electrical installations allows us to compare them. Thus, a UHF electrical installation of the first type, due to non-thermal UHF modification, gives polymers new essential properties.
For example, epoxy compounds harden faster, polymer filaments and fibres withstand higher breaking loads, polysulfone films become more elastic. But these processes take place practically without heating, at an intensity E, which requires the supply of a UHF power of hundreds and thousands of watts to the working chamber. This power is forcedly dissipated in the ballast load so that the efficiency of the working chamber for using UHF energy is practically equal to 0 .

In the UHF electric installation proposed in this work with a hybrid-type working chamber, the UHF power remained after the non-thermal UHF modification is spent on the thermal UHF modification of another dielectric. And the efficiency of the entire installation for using UHF energy becomes acceptable, and the installation receives tremendous practical interest.

\section{FINDINGS}

The design of a new type of UHF electric installation with a hybrid-type working chamber is proposed, which allows simultaneous non-thermal UHF modification of a polymer object and thermal UHF modification of any other dielectric.

It is proposed to use a UHF electric installation with a hybrid-type working chamber instead of separate UHF electromagnetic installations that implement only a nonthermal UHF modification of a polymer object or a thermal UHF modification of a dielectric material or product.

The UHF power remaining after the non-thermal modification of the UHF power in the UHF electrical installation with a hybrid-type working chamber enters the thermal UHF modification's working chamber. There it is spent on heat treatment of the dielectric object. The installation's efficiency for using UHF energy turns out to be all worthy and is mainly determined by the working chamber thermal UHF modification. If this is a travelling wave camera, then this efficiency reaches $98 \%$. In the proposed UHF electrical installation with a hybrid-type working chamber, due to a non-thermal modification, the curing of epoxy compounds is accelerated by 10-50 times, the tensile strength of polycaproamide threads increases by 1.5 times. In the technological unit of thermal UHF modification, travelling wave chambers, beam-type chambers, meander-type chambers can be used. Any of the working chambers known today makes it possible to carry out non-thermal UHF modification of objects of different sizes and with different parameters.

The procedure and content of designing a UHF electric installation with a hybrid-type working chamber are proposed.

\section{PRACTICAL APPLICATION AND RESULTS}

The practical application of a UHF electric installation with a hybrid-type working chamber increases the profit from the production of modified objects. Such an installation takes up a smaller area and increases the enterprise's representation in the product market.

\section{REFERENCES}

[1] Tukhvatullin, M.I., Aipov, R.S. (2019). Technological 
installation for UHF drying of sawn timber. Questions of Electrical Technology, 4: 12-18.

[2] Aipov, R.S., Gabitov, I.I., Tuhvatullin, M.I., Linenko, A.V., Tuktarov, M.F., Akhmetshin, A.T. (2019). Process unit for drying sawn timber rotating in the ultra high frequency field with a discrete arrangement of magnetrons. Bulgarian Journal of Agricultural Science, 25(S2): 3-11.

[3] Tukhvatullin, M.I. (2019). Results of experimental studies of sawn timber drying in a UHF installation. Electrotechnology Issues, 4: 50-56.

[4] Arkhangelsky, Y.S., Kalganova, S.G., Yafarov, R.K. (2018). Measurements in UHF electrical installations. Amirit, Saratov. (In Russian). https://www.elibrary.ru/item.asp?id=19576753.

[5] Dobrodum, A.S., Arkhangelsk, Y.S. (2017). Terminological base, energy efficiency and power supply of UHF electrical installations. Electrotechnology Issues, 1: 94-102.

[6] Karampatea, A., Siakavara, K. (2018). Analysis and synthesis of double negative dielectric media rectenna systems for ambient microwave energy harvesting. International Journal of Antennas and Propagation, 2018: 2472738. https://doi.org/10.1155/2018/2472738

[7] Monton, C., Luprasong, C., Charoenchai, L. (2019). Convection combined microwave drying affect quality of volatile oil compositions and quantity of curcuminoids of turmeric raw material. Revista Brasileira de Farmacognosia Issues, 29: 434-440. https://doi.org/10.1016/j.bjp.2019.04.006

[8] Nirmaan, A.M.C., Prasantha, B.R., Peiris, B.L. (2020). Comparison of microwave drying and oven-drying techniques for moisture determination of three paddy (Oryza sativa L.) varieties. Chemical and Biological Technologies in Agriculture, 7(1): 1-7. https://doi.org/10.1186/s40538-019-0164-1

[9] Szałatkiewicz, J., Kalinowski, M., Szewczyk, R. (2017). Investigation of newly developed microwave heated moisture analyzer measurements of ketchup and milk samples in climatic chamber. In International Conference Mechatronics, pp. 377-383. https://doi.org/10.1007/9783-030-15857-6_37

[10] Xu, F., Chen, Z., Huang, M., Li, C., Zhou, W. (2017). Effect of intermittent microwave drying on biophysical characteristics of rice. Journal of Food Process Engineering, 40(6): e12590. https://doi.org/10.1111/jfpe.12590

[11] Dobrodum, A.S., Arkhangelsk, Y.S. (2017). UHF electric installations with hybrid cameras. Electrotechnology Issues, 3: 16-22. (In Russian). https://www.elibrary.ru/item.asp?id=32473971.

[12] Li, H., Qu, Y., Yang, Y., Chang, S., Xu, J. (2016). Microwave irradiation-A green and efficient way to pretreat biomass. Bioresource Technology, 199: 34-41. https://doi.org/10.1016/j.biortech.2015.08.099

[13] Khasanov, E.R. (2015). Influence of treatment modes with UHF currents on disinfection and stimulation of seed germination with subsequent incrustation. Bulletin of the Bashkir State Agrarian University, 3(35): 77-81. (In

Russian) https://www.elibrary.ru/item.asp?id=24305111.

[14] Sivyakov, B.K., Grigoryan, S.V. (2019). Mathematical modeling of a multi-wave UHF installation for drying products. Electrotechnology Issues, 4(25): 5-11. (In
Russian).

https://www.elibrary.ru/item.asp?id=43019037.

[15] Stepanenko, V.V., Kazhevnikov, V.Y. (2017). Disinsection of food products with the energy of UHF electromagnetic field. Electrotechnology Issues, 4(17): 19-22. (In Russian). https://www.elibrary.ru/item.asp?id=32855829.

[16] Weng, X., Zhou, Y., Fu, Z., Gao, X., Zhou, F., Jiang, J. (2021). Effects of microwave pretreatment on drying of $50 \mathrm{~mm}$-thickness Chinese fir lumber. Journal of Wood Science, 67(1): 1-9. https://doi.org/10.1186/s10086-02101942-2

[17] Zlobina, I.V. (2018). Low-temperature hardening modification of cured polymer composite materials in a UHF electromagnetic field. Questions of Electrical Technology, 4(21): 16-23. (In Russian). https://www.elibrary.ru/item.asp?id=37344274.

[18] Trigorly, S.V., Zakharov, V.V., Alekseev, V.S. (2019). Numerical modeling of the processes of melting of dielectrics in microwave devices of the beam type. Electrotechnology Issues, 2(23): 13-19. (In Russian). https://www.elibrary.ru/item.asp?id=40631888.

[19] Tukhvatullin, M.I., Aipov, R.S., Linenko, A.V., Galiullin, R.R., Kamalov, T.I. (2019). Microwave drying of wood, mathematical simulation of rotating lumber in the SHF field. International Journal of Advanced Science and Technology, 28(9): 208-218.

[20] Zakharov, V.V., Yankin, S.V., Trigorly, S.V. (2018). Numerical modeling of processes of UHF heat treatment of large-area dielectrics using UHF installations of methodical operation. Electrotechnology Issues, 3(20): 36-41. (In Russian). https://www.elibrary.ru/item.asp?id=37101483.

[21] Chen, J., Wang, W., Lin, H., Chen, H. (2018). Influence of electromagnetic characteristics of sodium chloride on temperature change during microwave drying. In the International Multidiscipline Conference on Optofluidics, 531: 41-47. https://doi.org/10.1007/978-981-13-338118

[22] Feng, S., Deng, J., Yu, L., Dong, Y., Zhu, Y., Fu, Y. (2020). Development of lightweight polypyrrole/cellulose aerogel composite with adjustable dielectric properties for controllable microwave absorption performance. Cellulose, 27(17): 10213-10224. https://doi.org/10.1007/s10570-020-03497-9

[23] Ghasri, M., Bouhendi, H., Kabiri, K., Zohuriaan-Mehr, M. J., Karami, Z., Omidian, H. (2019). Superabsorbent polymers achieved by surface cross linking of poly (sodium acrylate) using microwave method. Iranian Polymer Journal, 28(7): 539-548. https://doi.org/10.1007/s13726-019-00722-6

[24] Hong, S., Kim, H. (2019). Robust synthesis of coal bottom ash-based geopolymers using additional microwave heating and curing for high compressive strength properties. Korean Journal of Chemical Engineering, 36(7): 1164-1171. https://doi.org/10.1007/s11814-019-0286-y

[25] Hu, M., Zhang, N., Shan, G., Gao, J., Liu, J., Li, R.K. (2018). Two-dimensional materials: Emerging toolkit for construction of ultrathin high-efficiency microwave shield and absorber. Frontiers of Physics, 13(4): 1-39. https://doi.org/10.1007/s11467-018-0809-8

[26] Jia, T., Zheng, N.N., Cai, W. Q., Zhang, J., Ying, L., Huang, F., Cao, Y. (2017). Microwave-assisted one-pot 
three-component polymerization of alkynes, aldehydes and amines toward amino-functionalized optoelectronic polymers. Chinese Journal of Polymer Science, 35(2): 269-281. http://dx.doi.org/10.1007/s10118-017-1890-0

[27] Liu, T. S., Liu, N., An, Q.D., Xiao, Z.Y., Zhai, S.R., Li, Z.C. (2019). Designed construction of composites with enhanced UHF absorption performance. Journal of Alloys and Compounds, 802: 445-457. https://www.Xmol.com/paperRedirect/5736489

[28] Zhan, L., Li, W., Wang, G., Zhao, X., Li, Y., Wang, N. (2020). Effect of low temperature microwave drying on properties of dyed cashmere fibers. Fibers and Polymers, 21(3): 564-570. http://dx.doi.org/10.1007/s12221-0209713-2

[29] Zhang, L., Du, W., Nautiyal, A., Liu, Z., Zhang, X. (2018). Recent progress on nanostructured conducting polymers and composites: Synthesis, application and future aspects. Science China Materials, 61(3): 303-352. https://doi.org/10.1007/s40843-017-9206-4

[30] Bulat, M.P., Bulat, P.V., Denissenko, P.V., Esakov, I.I., Grachev, L.P., Volkov, K.N., Volobuev, I.A. (2018). Ignition of lean and stoichiometric air-propane mixture with a subcritical microwave streamer discharge. Acta Astronautica, 150: https://doi.org/10.1016/j.actaastro.2017.11.030

[31] Bulat, P.V., Zasukhin, O.N., Upyrev, V.V., Silnikov, M. V., Chernyshov, M.V. (2017). Base pressure oscillations and safety of load launching into orbit. Acta Astronautica, 135:

$150-160$. https://doi.org/10.1016/j.actaastro.2016.11.042

[32] Yudina, V.O., Arkhangelsky, Y.S. (2019). Transport systems of UHF electrical installations on hybrid-type chambers. Electrotechnology Issues, 4: 38-43. 